DOI: $10.21448 / \mathrm{ijsm} .404114$

\title{
Chemical Composition and Insecticidal Activity of Origanum syriacum L. Essential Oil Against Sitophilus oryzae and Rhyzopertha dominica
}

\author{
Tunay Karan ${ }^{(\mathbb{D} 1}$, Seyda Simsek ${ }^{(\mathbb{D})}$, Ilyas Yildiz $^{(\mathbb{D} 1}$, Ramazan Erenler ${ }^{\left(\mathbb{D}{ }^{* 1}\right.}$ \\ ${ }^{1}$ Plant Research Laboratory, Department of Chemistry, Faculty of Arts and Sciences, Gaziosmanpasa \\ University, Tokat, Turkey \\ ${ }^{2}$ Department of Plant Protection, Faculty of Agriculture, Bozok University, Yozgat, Turkey
}

\begin{abstract}
Origanum genus belonging to the Lamiaceae family is aromatic and medicinal plant. It has been used in many countries for medicinal and pharmaceutical purpose. Aerial part of the Origanum syriacum L. was dried at shade. The essential oil was generated by steam distillation and compounds were identified by GC-MS analysis. $\gamma$-terpinene (26.7\%), thymol (26.6\%) and carvacrol (22.9\%) was detected as the mail constituents. The essential oil was tested for insecticidal activity against adult of Sitophilus oryzae (L.) (Coleoptera: Curculionidae) and Rhyzopertha dominica (F.) (Coleoptera: Bostrychidae) using fumigation method. Essential oil revealed the excellent fumigant effect on $R$. dominica adults with a median lethal concentration $\left(\mathrm{LC}_{50}\right)$ value of $0.124 \mu \mathrm{L} / \mathrm{L}$ and $0.107 \mu \mathrm{L} / \mathrm{L}$ for $48 \mathrm{~h}$ and $72 \mathrm{~h}$ respectively. $\mathrm{LC}_{50}$ values of $S$. oryzae were found as $0.173 \mu \mathrm{L} / \mathrm{L}$ and $0.135 \mu \mathrm{L} / \mathrm{L}$ for $48 \mathrm{~h}$ and $72 \mathrm{~h}$ respectively. As a result, essential oil of $O$. syriacum has a potency to be a natural insecticide.
\end{abstract}

\section{ARTICLE HISTORY}

Received: 12 January 2018

Revised: 04 March 2018

Accepted: 11 March 2018

\section{KEYWORDS}

Origanum syriacum,

Insecticidal activity,

Fumigant toxicity,

Essential oil

\section{Introduction}

Plants include numerous fascinating compounds revealing plenty of biological activities [1-4]. Therefore, they play an important role in drug discovery and development process. Origanum genus belonging to Lamiaceae family, mainly distributed through the Mediterranean region and the Balkans has been represented almost 50 species through the world, fourteen of which are endemic for Turkey [5]. Origanum plant consumed as herbal tea and has been used for traditional medicine since ancient times as stimulating, antirheumatic, antispasmodic, and has antibacterial effects to treat various illness such as revulsion, dyspepsia, muscle contraction, diarrhea and infection diseases [6]. The secondary metabolites isolated from $O$. rotundifolium and $O$. majorana displayed the significant antiproliferative and antioxidant activities [7, 8]. Origanum species are well known for their essential oils which employ in flavoring agent mainly for meat, fish, soup and bottled food [9]. Carvacrol, caryophyllene, terpinene and thymol are the dominant essential oil compounds of Origanum revealing the significant biological activities [10]. Origanum demand has been increasing steadily in the world market, on accounts of the significance in food, pharmaceutical and cosmetic industries [11].

CONTACT: Ramazan Erenler $₫$ rerenler@gmail.com Gaziosmanpasa University, Department of Chemistry, Faculty of Arts and Sciences, Plant Research Laboratory, Tokat, Turkey 
Insect pests have threatened the crop production all over the world. Synthetic insecticides such as methyl bromide and phosphine fumigants have been used extensively to destroy stored pets and to protect stored food, feedstuffs, and agricultural materials [12]. However, widespread usage of fumigants has brought about the development of resistance in stored-product insects [13]. Moreover, owing to the depleting of ozone layer, residue forming, and carcinogenicity, some synthetic insecticides have been prohibited $[14,15]$. As a result, it is essential to find novel fumigants which should be harmless to the environment, ecosystem, and non-target organisms to combat stored product insects. Natural products, especially essential oils have gained the great interest to replace synthetic products in fighting pets recently [16]. The rice weevil, Sitophilus oryzae and bean weevil, Rhyzopertha dominica are the most widespread and destructive insect pests of stored grains as well as stored products [17, 18].

Essential oils (EOs) exhibiting a broad spectrum of biological activities are generated from various aromatic plants. EOs have been extensively used in food and pharmaceutical industry [19]. Moreover, due to the their insecticidal effect, they have been employed in agricultural purpose [20].

Herein, the essential oil of $O$. syriacum was generated by steam distillation and identified by GC-MS. In addition, insecticidal activity test of essential oil was carried out against $S$. oryzae and $R$. dominica. The results revealed that the essential oil exhibited excellent insecticidal activity against these pets.

\section{Material and Methods}

\subsection{Plant Material}

The aerial parts of cultivated Origanum syriacum were harvested from the Medicinal and Aromatic Plant Field of Gaziosmanpasa University, Tokat, Turkey and identified by Prof. Dr. Ozgur Eminagaoglu. A voucher specimen was deposited in the Herbarium of the Faculty of Forest Engineering (ARTH: 5256) Artvin Coruh University.

\subsection{Isolation of the Essential Oils}

Aerial parts of plant material $(50 \mathrm{~g})$ were diluted with distillated water $(250 \mathrm{ml})$ then subjected to hydrodistillation for $4 \mathrm{~h}$, using a Clevenger apparatus. The oil was dried over sodium sulphate and stored in the freeze $\left(4^{\circ} \mathrm{C}\right)$ until to be analyzed.

\subsection{GC and GC-MS Analysis}

GC analyses were performed on a Perkin-Elmer Clarus 500 Series, in divided mode, 50:1, equipped with a flame ionization detector (FID) (Perkin-Elmer Clarus 500) and a mass spectrometer-equipped (Perkin-Elmer Clarus 500) BPX-5 capillary column $(30 \mathrm{~m} \times 0.25 \mathrm{~mm}$, 0.25 um i.d., SGE Analytical science- Trajan scientific and medicinal). The temperature of injection was steady and FID was performed at $250^{\circ} \mathrm{C}$. Helium was the carrier gas at a rate of $1.0 \mathrm{ml} / \mathrm{min}$. The oven temperature was $50{ }^{\circ} \mathrm{C}$ at the beginning then was raised to $220{ }^{\circ} \mathrm{C}$ with a rate of $8{ }^{\circ} \mathrm{C} / \mathrm{min}$. In the mass spectrometer, ionization energy was $70 \mathrm{eV}$ and the temperature of transfer line was at $250^{\circ} \mathrm{C}$. The standard components were used for the majority of the essential oil constituents and Kovats retention indices (RIs) were determined for all the sample

components using the Van den Dool and Kratz equation according to homolog n-alkane series retention times.

\subsection{Insect}

The cultures of $S$. oryzae and $R$. dominica were supplied from Department of Plant Protection, Bozok University. One third of $5 \mathrm{~L}$ glasswares were filled with clean wheat, and then adult males and females were added to lay eggs to get a single aged population. After the adults were removed, cultures were incubated at $27 \pm 2{ }^{\circ} \mathrm{C}$ in a dark climate chamber with $60 \pm$ 
$5 \%$ r.h. (relative humidity) for $48 \mathrm{~h}$. The new generation of adults came into view by 45 day and 3-4 week-old adults were used in tests [21].

\subsection{Dose-Response Bio-Assay}

Insecticidal activity of essential oil was determined by fumigation method. Conducted dose effect on $S$. oryzae and $R$. dominica of $O$. syriacum was carried out. In the experiments, 5, 10, 15 and $20 \%(\mathrm{v} / \mathrm{v})$ (essential oil/acetone) concentrations of the essential oil were used. Compressed rubber-capped glass tubes $(20 \mathrm{ml})$ were used. Small paper discs were cut and then they are fixed to the cover and 10 adult specimens were situated in the each glass. $10 \mu$ l volume of the oil mixture was saturated to the filter papers by pipettes. After this process, it was waited for 5 minutes to volatilize the acetone. Then the caps were covered on the glasses and they were waited in the incubator at $25^{\circ} \mathrm{C}$ in dark conditions for $24-48$ and 72 hours. The dead specimens were counted and recorded for each 24 hours interval. The randomized block design was used for the study. All experiments were repeated 3 times and each repetition consists of 3 replications [22].

\subsection{Statistical Analysis}

Dose-mortality response data from the bioassays were tested by POLO-PC probit analysis to determine the $\mathrm{LC}_{50}, \mathrm{LC}_{90}$, confidence level. The differences of $\mathrm{LC}_{50}, \mathrm{LC}_{90}$ were executed by comparison of confidence levels [23].

\section{Results and Discussion}

Origanum species are well known with their rich essential oils contents which are clear red color, a pleasant and slightly spicy odor. In this study, EO analysis was executed by GCMS and 14 components were identified with a rate of higher than $0.1 \%$, representing $99.8 \%$ of the oil (Table 1). $\gamma$-Terpinene, thymol were the main compounds, at $26.7 \%$ and $26.6 \%$ respectively; carvacrol, p-cymene, monoterpenes which are the second most abundant compounds, were present at $22.9 \%$ and $13.3 \%$ respectively.

Table 1. Chemical composition of $O$. syriacum essential oil analyzed by GC-MS

\begin{tabular}{llcc}
\hline No & Compounds & RI & Percent $(\%)$ \\
\hline 1 & $\alpha$-Thujene & 935 & 0.71 \\
2 & $\alpha$-Pinene & 941 & 1.07 \\
3 & Camphene & 955 & 0.13 \\
4 & Myrcene & 991 & 2.69 \\
5 & $\alpha$-Terpinen & 1021 & 4.27 \\
6 & $p$-Cymene & 1027 & 13.32 \\
7 & $\gamma$-Terpinene & 1067 & 26.66 \\
8 & $\alpha$-Terpinolen & 1092 & 0.15 \\
9 & Borneol & 1169 & 0.12 \\
10 & Terpinen-4-ol & 1181 & 0.44 \\
11 & $\alpha$-Terpineol & 1192 & 0.12 \\
12 & Thymol & 1291 & 26.62 \\
13 & Carvacrol & 1305 & 22.91 \\
14 & $\beta$-Caryophyllene & 1418 & 0.58 \\
& Total & & 99.79 \\
\hline
\end{tabular}

RI: Retention indices calculated against n-alkanes, \% calculated from FID data

In this work, fumigation assay was executed to investigate the toxicity of $O$. syriacum essential oil against adults of $S$. oryzae and $R$. dominica at four different concentrations. EO revealed the most fumigant effect on $R$. dominica adults with a median lethal concentration 
$\left(\mathrm{LC}_{50}\right)$ value of $0.124 \mu \mathrm{L} / \mathrm{L}$ at the confidence level of $0.100-0.140$ for $48 \mathrm{~h}$. Fumigation effect of EO increased with the time-dependence. $\mathrm{LC}_{50}$ value of $R$. dominica was $0.107 \mu \mathrm{L} / \mathrm{L}$ which was the best activity among the trials for $72 \mathrm{~h}$. However, $\mathrm{LC}_{50}$ values of $S$. oryzae adults were calculated as $0.173 \mu \mathrm{L} / \mathrm{L}$ and $0.135 \mu \mathrm{L} / \mathrm{L}$ for $48 \mathrm{~h}$ and $72 \mathrm{~h}$ respectively. While comparing $\mathrm{LC}_{90}$ for $R$. dominica adults and $S$. oryzae adults, significant differences were detected. LC 90 values of $R$. dominica adults and $S$. oryzae adults were calculated as $0.198 \mu \mathrm{L} / \mathrm{L}$ and $0.272 \mu \mathrm{L} / \mathrm{L}$ for $48 \mathrm{~h}$ respectively. Moreover, these values ( $\mathrm{LC}_{90}$ ) were found as $0.192 \mu \mathrm{L} / \mathrm{L}$ and $0.222 \mu \mathrm{L} / \mathrm{L}$ for $R$. dominica and $S$. oryzae for $72 \mathrm{~h}$ respectively (Table 2).

Table 2. Fumigant effect of $O$. syriacum essential oil on $R$. dominica and S. oryzae

\begin{tabular}{lcccc}
\hline Insects & hours & Slope $\pm \mathrm{SD}$ & $\begin{array}{c}\mathrm{LC}_{50}(\mu \mathrm{L} / \mathrm{L}) \\
(\text { Confidence level })\end{array}$ & $\begin{array}{c}\mathrm{LC}_{90}(\mu \mathrm{L} / \mathrm{L}) \\
(\text { Confidence level })\end{array}$ \\
\hline R. dominica & 48 & $17.166 \pm 2.790$ & 0.124 & 0.198 \\
& & & $(0.100-0.140)$ & $(0.181-0.226)$ \\
& & $15.114 \pm 2.233$ & 0.107 & 0.192 \\
S. oryzae & 48 & $13.014 \pm 1.520$ & $(0.082-0.125)$ & $(0.174-0.218)$ \\
& & & 0.173 & 0.272 \\
& 72 & $14.713 \pm 1.508$ & $(0.153-0.206)$ & $(0.231-0.360)$ \\
& & & 0.135 & 0.222 \\
& & & $(0.123-0.147)$ & $(0.202-0.251)$ \\
\hline
\end{tabular}

These results revealed a few differences regarding to the compounds and quantities with the literatures. For instance, O. syriacum collected from August at altitudes of 250-1900 m consisted of carvacrol and $p$ - cymene at $60.5 \%$ and $7.4 \%$ respectively. In the same work, it was reported that $O$. onites essential oil constituted carvacrol $(69.0 \%)$ as a chief product. Furthermore, carvacrol (\%39.1), thymol (22.2\%), and $p$-cymene (9.3\%) were found in EO of O. vulgare [24]. These results emphasized the important variability of chemical composition of Origanum oils through their components. These differences could be on account of various criterions such as part of the plant, harvest period, location, altitude, climate, environmental conditions. Indeed, the synthesis and secretion of oils are influenced by these factors [25].

Insecticidal activity of Origanum species EOs was executed against various insects that EOs displayed the considerable activity. For instance, O. majorana EO displayed the good fumigant activity against Spodoptera littoralis which was the serious pest of some crops such as cotton, chili, and tobacco [26]. The major compounds of $O$. majorana EO were detected as thymol (38.8\%), carvacrol $(32.9 \%), p$-cymene $(7.9 \%)$, and $\gamma$-terpinene $(5.1 \%)$. The chemical compounds of $O$. majorana have been similar with $O$. syriacum. Therefore, the insecticidal activity of $O$. syriacum may be due to the major constituents of essential oil components. Another work carried out in Algeria revealed that O.glandulosum has highly toxic potential power against Rhyzopertha dominica by both contact and fumigant assays [27].

Insecticidal components of most essential oils are usually monoterpene [28]. Because of the high volatility, essential oils have fumigant and gaseous action that may be significance for stored product insecticides. The carvracrol, a monoterpene has extensive insecticidal and acaricidal activity against agricultural stored product, and medicinal pests and act as a fumigant [29].

A good natural insecticide has been accepted that it influences a limited range of pest insects, has no harmful effects on non-target organisms and the environment, act in many ways on various types of pest complex [30]. Most plant extract and essential oils have been known to possess repellent and insecticidal activity against various stored product insects [31]. Some essential oils such as mustard oil, cinnamon oil and horseradish oil were reported to have strong 
effect against $S$. oryzae insect. In addition, essential oils generated from Pinus longifolia, Eucalyptus obliqua and Coriandrum sativum were tested for contact and fumigant activities against rice weevil, Sitophilus oryzae, Callosobruchus chinensis and Corcyra cephalonica and the results varied with the test material, insect species and exposure time. In fumigation assay, Corcyra cephalonica and Eucalyptus obliqua oils at $130 \mu \mathrm{g} / \mathrm{cm}^{2}$, led to $100 \%$ toxicity to all the species within the $24 \mathrm{~h}$ of the treatment [32].

\section{Conclusion}

O. syriacum essential oil has a potential for applications for stored-grain pests due to its high volatility and fumigant activity. In addition, EO of $O$. syriacum might be applicable for managing $S$. oryzae and $R$. dominica insects in enclosed spaces such as storage bins, glasshouses, or buildings due to their fumigant action. These results suggested that the insecticidal action of the oils might be due to the fumigant action. In other word, the oils could be toxic by penetrating the insect body via the respiratory system. The significant insecticidal activity of $O$. syriacum could be caused from $\gamma$-terpinene, thymol and carvacrol which were the major compounds of EO content. The major three compounds have methyl and isopropyl moiety. Thymol and carvacrol are constitutional isomers. In other words, both compounds have same molecular formula, $\mathrm{C}_{10} \mathrm{H}_{14} \mathrm{O}$ but different structural formulas. Methyl, isopropyl and hydroxyl connected to the phenyl group in thymol and carvacrol. Hence, methyl, isopropyl and hydroxyl bonded to the phenyl may be effective for the activity.

\section{Conflict of interest}

The authors declare that they have no conflict of interest.

\section{Orcid}

Tunay Karan (iD https://orcid.org/0000-0002-9114-8400

Seyda Simsek (D) https://orcid.org/0000-0002-0096-8949

Ilyas Y1ldiz (D) https://orcid.org/0000-0003-1254-1069

Ramazan Erenler (iD https://orcid.org/0000-0002-0505-3190

\section{References}

[1] Elmastas, M., Erenler, R., Isnac, B., Aksit, H., Sen, O., Genc, N., \& Demirtas, I. (2016). Isolation and identification of a new neo-clerodane diterpenoid from Teucrium chamaedrys L. Natural Product Research, 30 (3): 299-304.

[2] Erenler, R., Yilmaz, S., Aksit, H., Sen, O., Genc, N., Elmastas, M., \& Demirtas, I. (2014). Antioxidant Activities of Chemical Constituents Isolated from Echinops orientalis Trauv. Records of Natural Products, 8 (1): 32-36.

[3] Erenler, R., Sen, O., Yildiz, I., \& Aydin, A. (2016). Antiproliferative activities of chemical constituents isolated from Thymus praecox subsp grossheimii (Ronniger) Jalas. Records of Natural Products, 10 (6), 766-770.

[4] Demirtas, I., Erenler, R., Elmastas, M., \& Goktasoglu, A. (2013). Studies on the antioxidant potential of flavones of Allium vineale isolated from its water-soluble fraction. Food Chemistry, 136 (1), 34-40.

[5] Davis, P.H. (1998). Flora of Turkey and the East Aegean Islands. Edinburg, United Kingdom: University Press.

[6] Jun, W.J., Han, B.K., Yu, K.W., Kim, M.S., Chang, I.S., Kim, H.Y., \& Cho, H.Y. (2001). Antioxidant effects of Origanum majorana L. on superoxide anion radicals. Food Chemistry, 75 (4): 439-444. 
[7] Erenler, R., Sen, O., Aksit, H., Demirtas, I., Yaglioglu, A.S., Elmastas, M., \& Telci, I. (2016). Isolation and identification of chemical constituents from Origanum majorana and investigation of antiproliferative and antioxidant activities. Journal of the Science of Food and Agriculture, 96 (3): 822-836.

[8] Erenler, R., Meral, B., Sen, O., Elmastas, M., Aydin, A., Eminagaoglu, O., \& Topcu, G. (2017). Bioassay-guided isolation, identification of compounds from Origanum rotundifolium and investigation of their antiproliferative and antioxidant activities. Pharmaceutical Biology, 55 (1): 1646-1653.

[9] Busatta, C., Vidal, R.S., Popiolski, A.S., Mossi, A.J., Dariva, C., Rodrigues, M.R.A., Corazza, F.C., Corazza, M.L., Oliveira, J.V., \& Cansian, R.L. (2008). Application of Origanum majorana L. essential oil as an antimicrobial agent in sausage. Food Microbiology, 25 (1): 207-211.

[10] Economou, G., Panagopoulos, G., Tarantilis, P., Kalivas, D., Kotoulas, V., Travlos, I.S., Polysiou, M., \& Karamanos, A. (2011). Variability in essential oil content and composition of Origanum hirtum L., Origanum onites L., Coridothymus capitatus (L.) and Satureja thymbra L. populations from the Greek island Ikaria. Industrial Crops and Products, 33 (1): 236-241.

[11] Milos, M., Mastelic, J., \& Jerkovic, I. (2000). Chemical composition and antioxidant effect of glycosidically bound volatile compounds from oregano (Origanum vulgare L. ssp hirtum). Food Chemistry, 71 (1), 79-83.

[12] Athanassiou, C.G., Hasan, M.M., Phillips, T.W., Aikins, M.J., \& Throne, J.E. (2015). Efficacy of methyl bromide for control of different life stages of stored-product psocids. Journal of economic entomology, 108 (3), 1422-1428.

[13] Abouseadaa, H.H., Osman, G.H., Ramadan, A.M., Hassanein, S.E., Abdelsattar, M.T., Morsy, Y.B., Alameldin, H.F., El-Ghareeb, D.K., Nour-Eldin, H.A., \& Salem, R. (2015). Development of transgenic wheat (Triticum aestivum L.) expressing avidin gene conferring resistance to stored product insects. BMC plant biology, 15 (1): 183.

[14] Rajashekar, Y., Ravindra, K., \& Bakthavatsalam, N. (2014). Leaves of Lantana camara Linn. (Verbenaceae) as a potential insecticide for the management of three species of stored grain insect pests. Journal of food science and technology, 51 (11), 3494-3499.

[15] Jagadeesan, R., Nayak, M.K., Pavic, H., Chandra, K., \& Collins, P.J. (2015). Susceptibility to sulfuryl fluoride and lack of cross-resistance to phosphine in developmental stages of the red flour beetle, Tribolium castaneum (Coleoptera: Tenebrionidae). Pest management science, 71 (10), 1379-1386.

[16] Isman, M.B. (2006). Botanical insecticides, deterrents, and repellents in modern agriculture and an increasingly regulated world. Annu Rev Entomol, 51, 45-66.

[17] Aref, S.P., Valizadegan, O., \& Farashiani, M.E. (2015). Eucalyptus dundasii Maiden essential oil, chemical composition and insecticidal values against Rhyzopertha dominica (F.) and Oryzaephilus surinamensis (L.). Journal of Plant Protection Research, 55 (1), 35-41.

[18] Mishra, B.B., Tripathi, S., \& Tripathi, C. (2013). Bioactivity of two plant derived essential oils against the rice weevils Sitophilus oryzae (L.) (Coleoptera: Curculionidae). Proceedings of the National Academy of Sciences, India Section B: Biological Sciences, 83 (2), 171-175.

[19] Shaaban, H.A.E., El-Ghorab, A.H., \& Shibamoto, T. (2012). Bioactivity of essential oils and their volatile aroma components: Review. Journal of Essential Oil Research, 24 (2), 203-212. 
[20] Huang, Y., Lam, S., \& Ho, S. (2000). Bioactivities of essential oil from Elletaria cardamomum (L.) Maton. to Sitophilus zeamais Motschulsky and Tribolium castaneum (Herbst). Journal of Stored Products Research, 36 (2), 107-117.

[21] Abay, G., Karakoc, O.C., Tufekci, A.R., Koldas, S., \& Demirtas, I. (2012). Insecticidal activity of Hypnum cupressiforme (Bryophyta) against Sitophilus granarius (Coleoptera: Curculionidae). Journal of Stored Products Research, 51, 6-10.

[22] Polatoğlu, K., Karakoç, Ö.C., Yücel, Y.Y., Gücel, S., Demirci, B., Demirci, F., \& Başer, K.H.C. (2017). Insecticidal activity of Salvia veneris Hedge. Essential oil against coleopteran stored product insects and Spodoptera exigua (Lepidoptera). Industrial Crops and Products, 97: 93-100.

[23] LeOra Software (1994). Polo-PC a user's guide to probit or logit analysis. 1119 Shattuck Avenue, Berkeley, CA, 94707: USA.

[24] Schulz, H., Özkan, G., Baranska, M., Krüger, H., \& Özcan, M. (2005). Characterisation of essential oil plants from Turkey by IR and Raman spectroscopy. Vibrational Spectroscopy, 39 (2), 249-256.

[25] Khalfi, O., Sahraoui, N., Bentahar, F., \& Boutekedjiret, C. (2008). Chemical composition and insecticidal properties of Origanum glandulosum (Desf.) essential oil from Algeria. Journal of the Science of Food and Agriculture, 88 (9), 1562-1566.

[26] Souguir, S., Chaieb, I., Cheikh, Z.B., \& Laarif, A. (2013). Insecticidal activities of essential oils from some cultivated aromatic plants against Spodoptera littoralis (Boisd). Journal of Plant Protection Research, 53 (4), 388-391.

[27] Sahraoui, N., Hazzit, M., \& Boutekedjiret, C. (2017). Effects of microwave heating on the antioxidant and insecticidal activities of essential oil of Origanum glandulosum Desf. obtained by microwave steam distillation. Journal of Essential Oil Research: 1-10.

[28] Konstantopoulou, I., Vassilopoulou, L., Mavragani-Tsipidou, P., \& Scouras, Z. (1992). Insecticidal effects of essential oils. A study of the effects of essential oils extracted from eleven Greek aromatic plants on Drosophila auraria. Experientia, 48 (6), 616-619.

[29] Ahn, Y.-J., Lee, S.-B., Lee, H.-S., \& Kim, G.-H. (1998). Insecticidal and acaricidal activity of carvacrol and $\beta$-thujaplicine derived from Thujopsis dolabrata var. hondai Sawdust. Journal of Chemical Ecology, 24 (1), 81-90.

[30] Regnault-Roger, C. (1997). The potential of botanical essential oils for insect pest control. Integrated Pest Management Reviews, 2 (1), 25-34.

[31] El-Nahal, A., Schmidt, G., \& Risha, E. (1989). Vapours of Acorus calamus oil-a space treatment for stored-product insects. Journal of Stored Products Research, 25 (4), 211 216.

[32] Rani, P.U. (2012). Fumigant and contact toxic potential of essential oils from plant extracts against stored product pests. Journal of Biopesticides, 5 (2), 120. 